\title{
Constructing the Autonomous Patriotism on China's Weibo: the Case of "Ding Was Here"
}

\author{
Bei Guo \\ School of Journalism and Communication, \\ Shaanxi Normal University \\ Xi’an, Shaanxi Province, P.R.China \\ bei.guo@snnu.edu.cn
}

\begin{abstract}
Through analyzing the international incident known as 'Ding was here', which sparked a wave of national patriotism on Weibo, this study shows how the state plays a significant role in establishing the parameters for public debate to regulate social media in China. This study provides empirical evidence that furthers recent attempts to apply Foucauldian theories of governmentality to the case of China. It identifies "the invisible hand" of the Chinese state, as it attempts to embrace more sophisticated forms of governance in the regulation of Weibo. This study argues although Weibo provides a platform for political participation and public expression; it is still subject to heavy monitoring by the state through cultural control, which is a tactic of governmentality.
\end{abstract}

Keywords—governmentality; cultural control; patriotism

\section{INTRODUCTION}

The rise of the internet has profoundly transformed the ways that people communicate and has become an integrated part of our daily lives. In China, it is commonly held that the rise of the internet has provided ordinary people with an alternative channel to voice concerns. This power seems even stronger in the wake of social media platforms which have injected a new vitality into internet discussions. Weibo has been brought into Chinese society in 2008, though its history may be short, its spreading use is nonetheless breathtaking. Many scholars have looked to Weibo in China as offering the potential for transformation from great control to great freedom. Through this social media platform in contemporary China, one could begin to see a liberalization of freedom of speech in a reportedly illiberal society; Weibo has developed into a vital public communications arena for a lively and dynamic exchange of information, contentions, accusations and scandalous revelations.

However, with an autonomous sense of national embarrassment and subsequent debates on patriotism generated on Weibo as the result of a Chinese child's graffiti of "Ding was here" in an Egyptian temple, this study argues that the empowered "free" space on Weibo is actually constructed and manipulated by the Chinese government to fuel surging patriotic identity, in order to strengthen discipline in the Chinese people. This type of national patriotism drawing on a relatively small incident of failed travel etiquette contributes to the Chinese government's many years of ongoing work in shaping the Chinese people's national identity in the form of patriotism. In addition, this research analyses the Chinese government's astute and proactive timing in becoming involved in this incident, in order to serve its long term agenda. Through making commentaries in official newspapers and issuing relevant regulations, the intervention illustrates that, apart from its ongoing efforts to influence public awareness, the Chinese state has also displayed strategic planning in selectively choosing this incident to maximise its impact in reinforcing its political status quo. The case of "Ding was here" illustrates how contemporary Weibo is being used for government intervention in this populist Weibo phenomenon, to build on the state's earlier work in regulating people's hearts and minds to fit its national agenda and construct a politically useful narrative.

\section{BACKGROUND OF "DING WAS HERE"}

On May 24, 2013, a verified Weibo user named "kongyouwuyi" (Mr.Shen) posted a photo of an engraving in the 3,500-year-old Luxor Temple in Egypt which had been vandalised with Chinese graffiti saying "Ding Jinhao was here". The traveler wrote on the original Weibo post (see Figure 1), "It was the saddest moment during my stay in Egypt. I'm so ashamed that I want to hide myself. I said to the Egyptian tour guide, 'I'm really sorry'. Then we tried to wipe out the shame with tissue, but it was difficult to clear it out, and we could not use water." Immediately, this posting generated a massive online backlash among China's unforgiving netizens. The post was tweeted and retweeted and it sparked a heated discussion in China about etiquette when travelling abroad, with Ding Jinhao becoming the target of Chinese internet vigilantes. By May 25, 2013, there were more than 11,000 comments and as many as 83,000 retweets [13]. There were diverse online criticisms of the boy and his parents In addition, there were many debates about Chinese people's travelling etiquette and suzhi (quality) (see Figure 2), saying that Ding's bad manners had damaged the image of the Chinese people. 




Fig. 1. Photo of "Ding was here"

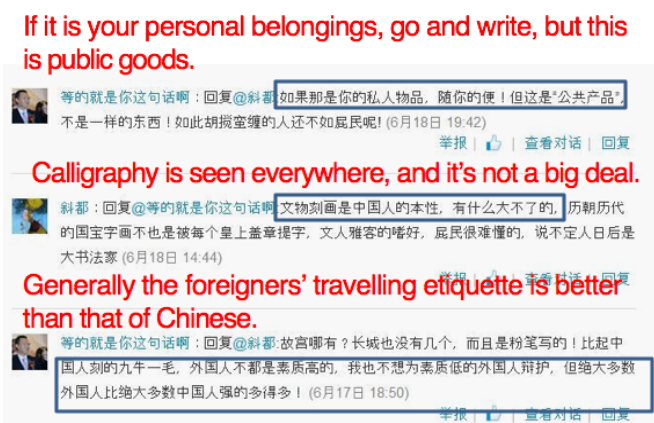

Fig. 2. Example of comments

In the meantime, the post prompted an online hunt for Ding Jinhao, with the internet vigilantes in China soon identifying him. He was a 14-year-old student. On May 25, a netizen revealed Ding's personal information through the aptly named human flesh search engine and posted it on Weibo, including his date of birth and the school he attended in Nanjing in eastern China's Jiangsu Province. Later that day, Ding's embarrassed parents made a public apology to both the Chinese people and to the Egyptian authorities for their son's wrongdoing. They told the Nanjing-based Modern Express newspaper: "We apologize to the Egyptian authorities and the Chinese people who were concerned about the incident. He has realized that he made a mistake, and we beg your pardon; please give him a chance to correct his act". Later, on May 26, the official website of the school Ding attended was hacked by vigilante netizens and defaced with a pop-up window on the website mimicking Ding Jinhao's vandalism. Visitors have to click "ok" on a message box which reads "Ding has visited this place" before they are granted access to the site. There were also calls to reflect on education and family influence, with Weibo users condemning Ding's parents for not educating him properly. Netizens argued about whether the behavior lost face for the Chinese people. There were a number of comments abusively attacking Ding himself (see Figure 3). Later that day, according to a report from the Xinhua News Agency, the graffiti had almost been removed.

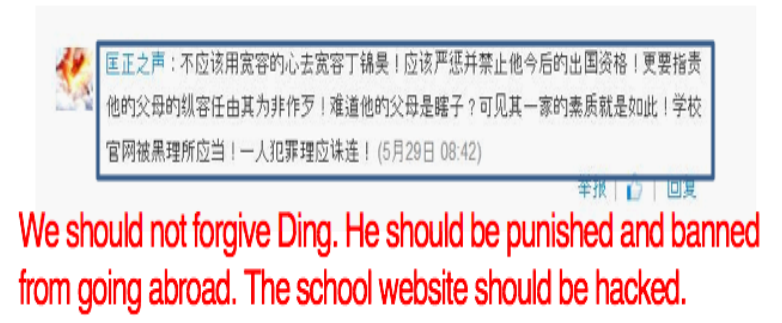

Fig. 3. Example of comments

\section{GROWTH IN CHINESE TOURISM}

In the following days, there were almost one hundred English reports on "Ding was here" when searched in Google. News agencies such as AFP, Reuters, CNN, the BBC and other influential media, had reported on this event, using widely applied negative terms such as 'destroy'and 'deface'.

In terms of the particular event that led to national embarrassment, one explanation may be that the Chinese state would like to improve China's global image and soft power. With China's economy booming over the past decade, a growing number of the country' s residents have become global tourists, fuelled by rising incomes and the relaxation of government restrictions on citizens' ability to travel abroad. According to a CNN report, in 2012, the Chinese have overtaken Americans and Germans as the world's top international tourism spenders [4]. In 2013, the number of outbound Chinese tourists was more than 90 million for the first time, and is expected to exceed 100 million in the next five years.

In the responses to Ding's incident, there was a tendency for emotional over-reaction, which indicates a lack of confidence and a sense of inferiority or shame within the Chinese nation. And Ding Jinhao is definitely not the first person with such "uncivilized" behavior. The poor behavior of Chinese tourists is often criticized by the media and meets a very strong response. The report from the Atlantic Wire also lists further instances where Chinese people have earned this reputation, such as at the Louvre in Paris, where the sign to warn people not to defecate and urinate on the premises is only in Chinese. There are Chinese tourists visiting the monks and temples in Thailand while disrespectfully wearing shorts. Chinese people are known for talking loudly. Moreover, according to this news, there were other similar incidents that caused public outrage in March 2009 when a man from Jiangsu province carved his name in a rock in Taiwan's Yehliu Geopark, and also in February 2013 when a visitor engraved their name in a cauldron at Beijing's Palace Museum.

This conflict in behaviors is not necessarily a new phenomenon. In 1992, a book called The Ugly Chinaman and the Crisis of Chinese Culture written by Bo Yang, was published in the English-speaking world, which included the author's speeches, writings and media interviews. Initially, this critique of the Chinese was banned in mainland China by Communist Party Officials. It was not until 2008 that Bo Yang's work, which in Chinese is called Ugly Chinese, crossed the seas and entered mainland China. This book 
described bad manners in Chinese culture, such as the rude, pushy behavior of the crowds, belching, wind-breaking, and spitting. He summarized Chinese people's characteristics as either arrogant or degraded, but certainly without dignity. The author contends that the problem goes back centuries. Bo Yang sharply describes this as "the putrid vat of soy sauce" (his phrase for the unpleasant side of China's otherwise fascinating culture) [2]. However, improving China's image and also strengthening its soft power could be a possible explanation for this congruence between shameful public behavior abroad and the empowered state agenda promoting China as a civilized nation. It does not quite explain the collective outpouring of emotions of national patriotism. Understanding this involves us in questions relating to the Chinese version of governmentality. These remarks on Chinese people's travelling etiquette showed the problematics of governmentality, that problems do not exist in themselves, rather, they become known "through grids of evaluation and judgment about objects that are far from self-evident" [5]. The study of government, then, entails modes of reasoning, employing various kinds of knowledge and agency to function in multiple ways (ibid).

\section{A WAVE OF NATIONAL EMBARRASSMENT AND NATIONAL PATRIOTISM}

The event of "Ding was here" sparked national embarrassment and a wave of public condemnation. One netizen said that "Ding's uncivilized behavior is a disgrace to our entire race" (see Figure 4), and another wrote: "This is not only a child's fault. I believe that many adults probably behave as badly. This is a national shame and the Chinese people really need to reflect. This "power effect" is conceptualized by Rose [5] that "free" actors are subject to new practices to construct identities for citizens to shape their conduct according to responsibility and self-conduct. In this incident, people are neatly divided into exclusive groups: patriots and non-patriots.

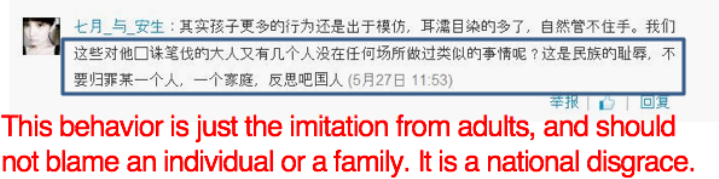

Fig. 4. Example of comments

Moreover, there were even death threats. The question on the minds of many at that moment was "why do Chinese people not behave properly?" An editorial of the People's Daily Online expressed the belief that the instance shows our families and schools have failed to deliver to the children something that should be expected first and foremost of any education: moral principles and civic virtues.

A small cultural incident about travel etiquette such as this would usually, at most, spark a debate about the citizens' awareness of the need to show respect towards public property and historical heritage. However, in an anonymous online survey conducted by Tencent to answer the question of whether the incident of "Ding was here" made you feel embarrassed and the Chinese people lose face, 85 percent of participants felt that this was true, while only 15 percent felt that it was not (see Figure 5).



Fig. 5. Online survey conducted by Tencent Company

Here a question can be asked: why did this small travel incident spark such great national embarrassment? China's cultural traditions offer a clear explanation. The Chinese have always cared strongly about appearances, and a level of appropriateness and dignity that they refer to as "face". They never want to lose face; they want always to show their absolute best. Since this behavior happened abroad, national image and pride come into play, therefore, it resulted in an extreme loss of face for the entire Chinese people. The rising economic development and global integration of China in recent years meant that the Chinese people are keen to improve their international image and status. However, in addition to the "loss of face" in this incident, there was a convergence between the public outcry and the government's ongoing efforts to build patriotic sentiment. This outpouring of spontaneous patriotism resonated with the instrumental technologies of government in usually advanced liberal regimes, and more recently used by the Chinese authorities.

In addition to the application of brute force to exercise control, modern government adopts certain strategies, techniques and procedures to render programs operable. In the construction of a strong sense of patriotism, the Chinese government uses a number of technologies to reach its aspirations. For example, inspiring imagination is an essential step for formation of group identity. It has been noted that "all communities larger than primordial villages of face-to-face contact (and perhaps even these) are imagined" [1]. In this way, communities are distinguished not by uniqueness but by their imagination. It is also true of nation and state. Therefore, throughout modern history, Western civilization and advanced culture have inevitably been "the other" in China's imagination, as contrasted with China reflecting the selfabasement, lack of confidence and aspiration of the Chinese. Particularly in the late 19th and early 20th centuries, China was referred to as the "sick man of East Asia" when it was riven by internal divisions and forced by great powers into a series of unequal treaties. Therefore, to a certain extent, this view reflects the way the Chinese have defined and positioned themselves in different historical periods. It also reflects the way the Chinese conceive their national identity. 


\section{TIMELY INVOLVEMENT OF MAINSTREAM MEDIA}

In "Ding was here", the Chinese government closely followed online chats in order to call public attention to travelling etiquette, as even possibly having an impact on government policies. The day after the public outcry over "Ding was here", the CCP mouthpiece, the People's Daily, picked it up and made a commentary to maximize its impact [10]. It could be seen that the government in fact prompts a popular reaction, and then follows it up. The interaction between mainstream media and Weibo is as follows: In the first step, the public has responded to the initiative to set the agenda, and then the mainstream media will selectively highlight certain cases to re-set the agenda, at the same time enabling the public discussion to reach a peak. Weibo users then widely forward the mainstream media commentaries. The government's responsiveness is a way of control through maximizing the impact of the story for its own purposes.

This incident gained enthusiastic support from the state and state-controlled media, and it is undeniable that this is particularly congruent with some of the core policies of the Chinese state. This event appeared in fact just a few days after China's government had attacked 'uncivilized' tourists for ruining the country's reputation abroad. Several days prior to the Ding Jinhao event, on May 16, at a meeting on a new tourism law of China, a senior Communist Party Official, Wang Yang, one of the country's four vice-premiers, warned Chinese tourists that they should be more polite when travelling, for example, not talking loudly in public, carving characters on tourist attractions, or crossing the road against the traffic lights, and activities such as spitting are considered poor behavior. He further stated that Chinese authorities should "guide tourists to conscientiously abide by public order and social ethics, respect local religious beliefs and customs, mind their speech and behavior and protect the environment" [3]. Wang also urged compatriots to project "a good image of Chinese tourists" and advocated for the nation's Tourism Law (ibid).

Therefore, this case reveals that online opinions easily gain the attention of the traditional media, which could be seen as a method to reinforce the central position of the mainstream media. In this way, the state-controlled, mainstream media remains dominant in "moulding" and constructing social responses and public opinion. Prior to national economic reform in 1978, the media was a Party propaganda apparatus, but in current times, once the appeal of online public opinion is congruent with government actions, the mainstream media reaffirms the dominance of its traditional function in directing public opinion. In this incident, the netizens influenced the agenda of the conventional media, and then the conventional media maintained the agenda by issuing propaganda commentaries. The function of the conventional media remains to perform a propaganda function in China and to correctly guide public opinion. Therefore, the event of "Ding was here" coincided with the national appeal of issuing tourism law.

In September, immediately before the Golden Week holiday that started on National Day October 1, which is one of the most popular times of year for the Chinese to travel,
China's National Tourism Administration publicised an illustrated 64-page 'Guidebook for Civilised Tourism'to instruct citizens on social norms overseas. It could also be accessed by people from its official website. China is not the first country to issue guidelines to travellers. Both locals and visitors on Tokyo subways, for example, will often encounter an ongoing series of 'etiquette tip' posters for consideration on public transport [11]. The booklet covers everything from reminders to say "please" and "thank you" and other specific rules of polite behavior in different countries. These books are printed with attractive cartoons and vivid illustrations. For example, do not ask questions like 'where are you going?' when greeting in the UK, and do not pick up your chopsticks before your elder. It also includes advice on etiquette on taking photos, toilet use, and queue jumping. Lessons learned from the globally publicised scandal, the Guide remind visitors, were to respect historical relics, and "not to scribble on, climb on or touch them". The guidebook of civilised tourism was a technique of the self, which served several purposes. It appeared during the Golden Week holiday, a time when the greatest number of tourists would be travelling or preparing to travel, therefore this action was able to immediately improve the tourists' image. Furthermore, it was able to educate and regulate people's behaviours. The 'Guidebook for Civilised Tourism' was distributed by some cities for free. This management of distributing brochures to improve citizens' behaviors demonstrates the amenability of tools in and of government control. In this case, government departments produce information handouts to educate the citizens to be "civilized". In addition, public relations experts could be employed to devise a number of advertising campaigns to generate public concern. This is one part of government technologies, which are "the complex of mundane programs, calculations, techniques, apparatuses, documents and procedures through which authorities seek to embody and give effect to governmental ambitions" [12].

On October 1, the Tourism Law of the People's Republic of China went into effect attempting to lay out rules to regulate China's tourism industry, addressing issues like tourist safety, unfair competition, price hikes and forced goods purchases, in order to promote sustained industry growth. There are several articles of the new law dealing with tourist behaviours. For example, Article 14 states: Tourists shall observe public order and respect social morality in tourism activities, respect local customs, cultural traditions and religious beliefs, care for tourism resources, protect the ecological environment, and abide by the norms of civilized tourist behaviors .

To widen the reach of improving citizen behavior, different media including television and newspapers, were used to broadcast the law. The patriotic sentiment engendered by "Ding was here" echoed by the Communist Party's flagship newspaper, the People's Daily. One day after this incident, in an article with the title of "hands are full but hearts are empty", the newspaper made the commentary that "nowadays, people in China no longer want for food and clothing, and even in the luxury shops abroad, there are advertising posters in Chinese, however, many people feel their hearts are empty because of lacking spiritual support" [10]. In the end, the paper wrote that 
'a visit' should become an opportunity to reflect our civilization. The heated discussion on Weibo, the emotions, the shame and the condemnatory tone, enable us to see a strong pursuit of civilization. Only by reflection on China's civilization could its citizens gain respect in the international arena, and move forward on the road to national rejuvenation (ibid). The way the government takes advantage of the internet incident to educate the public reveals a complicated picture of government networks that have become more adept in setting public agendas and regulating public discourse.

During the Weibo era, the measures the Chinese government has taken to build a nation-state can be seen as attempts to transmit an imaginary and patriotic construct to the masses. These methods involve more subtle and sustained forms of control over populations from which "subjects" can be brought to internalise state control through technologies of the self. These technologies permit "individuals to effect, by their own means, a certain number of operations on their own bodies, on their souls, on their own thoughts, on their own conduct, and this in a manner so as to transform themselves, modify themselves and to attain a certain state of perfection, of happiness, a purity, of supernatural power, and so on" [7]. In this way, the collective patriotic sentiment arising from "Ding was here" was constructed and fostered by the Chinese state through a number of measures. The next section will analyse the specific measures.

\section{A. Patriotic Education}

Since August 1994, China has formally proposed suzhijiaoyu, or Quality Education, which has been associated with ideas of education and proper behavior and has been incorporated into governmental educational and population programs in particular ways now implemented for almost 15 years. The concept of suzhijiaoyu in government education has become increasingly important over the 1990s, eventually becoming one of the guiding principles of education policy [6]

Together with the Quality Education framework, the government launched a program of 'patriotic education' in 1994. After the demonstrations in Tiananmen Square in 1989, the Chinese leaders realized that they had to pull China back to being a collective community with common goals in order to enable economic liberation in the wake of opening and reform policy. Therefore, readings on the pre-1949 history of the imperialists' aggression against China returned to the classroom. The Chinese government started a patriotic education campaign in 1992 and poured unprecedented resources into building people's patriotism. Initially, it was only included in primary and secondary schools, but later expanded to high schools and universities, aiming to enhance the patriotism of all Chinese people. In 1995, the government identified 100 patriotic books, films and songs recommended for young Chinese. The 1994 document, "Outlines for Patriotic Education", offered guidelines for teaching patriotism that included both cultural and political messages: the official Party line and Deng Xiaoping's theory of "socialism with Chinese characteristics" were the guiding principles. The purpose of this patriotic education was socialist modernization and the peaceful reunification of China, as well as to "rejuvenate" China's national spirit and to "reconstruct the sense of national esteem and dignity" [14]. Many studies have successfully explored and proved that Chinese political education textbooks helped to unify the diversified population and lead the general public into a national identity (ibid). Through professional disciplines and other forms of expertise, new ways of knowing the self and others can be achieved. In this way, the sentiment of national patriotism reflected in Ding further contributes to the ongoing patriotic education.

In addition to patriotic education, moral education was also implemented. Former Chinese President $\mathrm{Hu}$ Jintao said that the young should learn to 'love the motherland 'as a key virtue of 'socialist honour' (with harming the motherland being a signal of 'socialist disgrace'). Moral education that promotes feelings of nationalism should not be equated with 'propaganda', however, a pejorative term in the English language that likens state ideology to brainwashing [8]. After years of cultivation and education, people's responsibility and a historical sense of patriotism comes in a large measure, from their inner heart, especially in the younger generations. With the fast growth of the economy and China's increasing importance in the world, people have felt the automatic desire to shoulder historical responsibilities, which can been seen in the examples of earthquakes and other natural disasters. This type of automatic volunteerism and sense of responsibility is the fundamental reason for the national patriotism shown in the Ding event.

\section{B. Reviving Confucianism}

To construct individuals' identities, the communist regime has flexibly adjusted the content and boundaries of its hegemony over time. It has also constantly created new labels such as "three representations" and "harmonious society". It has been well known that it was difficult to align the two opposite philosophies of Marxism and Confucianism, with the former opposing class hierarchy but the latter accepting class inequity. However, in recent years the CCP has actively promoted the study of Confucianism and adapted certain terminologies into its ideology. Since China's opening to the outside world in 1978, the attitude towards Confucianism has changed, with, for example, increasing numbers of ethnic Chinese travelling to China in search of their roots (xungen). Confucianism was founded by Confucius, the renowned philosopher, educator and politician who lived from 551 to 479 BCE during the Han Dynasty. Not a religion, Confucius's teachings are basically the practical ethics or moral principles for dealing with daily life, which have long exerted influence in various aspects of Chinese society, such as family and cultural life. Admired for his wisdom, Confucius was followed by a host of disciples who recorded his teachings. Confucianism has special benefit to offer the party-state, for example, the well-being of the people, the notion of unity, and loyalty to the country.

The searching for cultural roots with the enforcement of Confucianism and collectivism, contributes significantly to economic growth. Hofstede and Bond investigate the reasons for East Asia's outperformance over other countries or regions such as South and Southeast Asia, as well as South America in the late 20th century, finding that in spite of Maoism, many 
Confucian values remain strong in the People's Republic [of China]" [9].

They summarized a series of core principles of Confucian teachings: 1) The stability of society is based on unequal relationships between people, for example, the basic relationship of ruler/subject, father/son, older brother/younger brother, husband/wife and older friend/younger friend. Thus, it suggests that inequality and power exist in any aspect of the society; 2) The family is the prototype of all social organizations. In this respect, a person should give up his/her individuality so as to maintain the collectivism or the harmony in the family. Further, Hofstede notes that the features of harmony or collectivism could be embodied in maintaining a person's 'face', which means one's dignity, self-respect, and prestige. Losing 'face 'or losing dignity is a serious matter in Chinese society; 3) Virtuous behavior towards others consists of treating others as one would like to be treated oneself, which emphasizes people's benevolence or loving; 4) Virtue with regard to one's tasks in life consists in trying to acquire skills and education, being thrifty, being patient and being moderate (ibid, p.8). The essence of Confucianism is one of the primary reasons for the formation of collective sentiment concerning national image and pride in response to the Ding event.

\section{CONCLUSION}

The analysis of "Ding was here" reveals that in contrast with the direct and hard censorship of the past, the Chinese authorities now engage with social media, notably Weibo, in more subtle ways, yet still with regulatory intentions. China's political ideologies and strategies today are aimed at maintaining state stability and defending the current political system, thus policies and regulations are targeted at maintaining the political status quo. Despite the fact that the Chinese state is considered an authoritarian regime, it employs a number of alternative technologies to shape and normalize the conduct of the Chinese. Therefore, in the case of "Ding was here", harnessing a strong patriotic passion is a vital step in influencing opinions in favor of the political status quo. In this respect, the Communist Party has used the Quality Education campaign and the Patriotic Education campaign to construct and shore up a patriotism that serves to maintain social stability. The goal of media govern mentality in China, to extend Foucault's point, is to cultivate a well-disciplined, highly moral and politically-compliant citizenry through the arts of re-inventing or sustaining traditions such as Confucianism, collectivism or patriotism to support the construction of national identity.

As the case of "Ding was here" suggests, Weibo users 'attitudes and values are still heavily influenced by the mainstream cultural values of collectivism and patriotism, which show an enforcing trend in the virtual communities. It suggests that Weibo is being used for pedagogical and control reasons under the guise of social media entertainment, by which subtle ideological constructs - such as collectivism and patriotism are being shown on Weibo, which was originally simply a new form of social media. It is noteworthy that the interaction between the mainstream media and Weibo helps the government to set its agenda and to achieve its purposes. In this case, once an online contention reaches a certain level, the government becomes alerted, the authorities then take action to cool down public emotions and to guide the public appropriately.

Therefore, though many studies view social media as offering tools of democracy, much of the traffic on China's Weibo merely serves to spread rumours and irrational or trivial discussions. More significantly, China's Weibo still serves as a tool for supervision by the state, suggesting that social media in China forms at best, a limited version of the public sphere.

\section{REFERENCES}

[1] Anderson, B 2006, Imagined Communities, Verso, New York and London.

[2] Bo, Y 1992, The ugly China man and the crisis of Chinese culture, Allen \& Unwin, New York.

[3] Cheung, S 2013, 'Dire manners and "uncivilized behavior" of tourists is harming China's image, admits VP Wang Yang', South China Morning Post, 18 May, viewed 22 August 2013, <http://www.scmp.com/news/china/article/1240206/dire-manners-anduncivilised-behaviour-tourists-harming-chinas-image?page=all.

[4] Cripps, K 2013, 'Chinese travelers the world's biggest spenders', CNN, 12 April, viewed 22 October 2013, <http://edition.cnn.com/2013/04/05/travel/china-tourists-spend/>

[5] Dean, M \& Hindess B 1998, 'Introduction: Government, Liberalism, Society', in Dean, M \& Hindess, B (eds.), Governing Australia: Studies in Contemporary Rationalities of Government, Cambridge University Press, Cambridge, pp.1-19.

[6] Dello-Iacovo, B 2009, 'Curriculum reform and "quality education" in China: an overview', International Journal of Educational Development, vol. 29, no. 3, pp. 241-249.

[7] Foucault, M 1993, 'About the beginning of the hermeneutics of the self: Two lectures at Dartmouth', Political theory, vol. 21, no. 2, pp. 198-227.

[8] Gries, PH 2004, China's new nationalism: Pride, politics and diplomacy, University of California Press, Berkeley.

[9] Hofstede, G \& Bond, MH 1988, 'The Confucius connection: From cultural roots to economic growth', Organizational dynamics, vol. 16, no. 4, pp. 5-21.

[10] Li, H 2013, 'Hands full with heart empty', People's Daily, 27 May, viewed 22 September 2013, <http://opinion.people.com.cn/n/2013/0527/c1003-21619899.html.

[11] McNeice, S 2013, 'Chinese authorities issued guidebook for "civilized tourism", 10 October, viewed 22 October 2013,<https://www.newstalk.ie/reader/47.339/14831/show_list_0_0/

[12] Miller, P \& Rose, N 1990, 'Political rationalities and technologies of government', in Hanninen, S and Palonen, K (eds.), Texts, Contexts, Concepts: Studies in Politics and Power in Language, Finnish political Science Association, Helsinki, pp.171-183.

[13] Pan, H 2013, 'Too ashamed to go to Egypt after the scandal', Xinhua News, 26 May, viewed 5 June 2013, <http://news.xinhuanet.com/world/2013-05/26/c_124763897.html

[14] Pykett, J 2010, 'Citizenship education and narratives of pedagogy', Citizenship Studies, vol. 14, no. 6, pp. 621-635.. 